Check for updates

Cite this: RSC Adv., 2017, 7, 27214

Received 1st April 2017

Accepted 17th May 2017

DOI: $10.1039 / c 7 r a 03750 c$

rsc.li/rsc-advances

\section{Dehalogenation of diatrizoate using nanoscale zero-valent iron: impacts of various parameters and assessment of aerobic biological post-treatment $\dagger$}

\begin{abstract}
Pan-Pan He, Chuan-Shu He, Qi Liu and Yang Mu (DD*
This study investigated the feasibility of nanoscale zero-valent iron (nZVI) for reductive dehalogenation of iodinated contrast medium diatrizoate (DTA). The impacts of various parameters, including nZVI dosage, DTA concentration, solution $\mathrm{pH}$, aging time of $\mathrm{nZVI}$, the presence of natural organic matter, and the type of competitive anions, on the dehalogenation of DTA as well as the formation of its reductive product 5diacetamidobenzoate (DABA) using nZVI were evaluated. Furthermore, an aerobic biological posttreatment was conducted to study the biodegradability of reductive products of DTA dehalogenation using nZVI. The results showed that dosing with $0.5 \mathrm{~g} \mathrm{~L}^{-1} \mathrm{nZVI}$ particles resulted in a rapid decrease in DTA concentration and a corresponding rise of the concentrations of DABA and $\mathrm{I}^{-}$. DTA dehalogenation in terms of its removal and DABA formation was enhanced with the increase in nZVI dosage but deteriorated when increasing solution $\mathrm{pH}$. nZVI aging time had a negative impact on DTA dehalogenation. Natural organic matter at much low level could improve DTA dehalogenation, while had a negative influence at high concentrations. Contrary to sulfate, the presence of nitrate and phosphate strongly inhibited DTA removal using nZVI. The results also showed that the reductive product DABA could be degraded by aerobic biological post-treatment, suggesting DTA dehalogenation with nZVI may be a vital procedure for its biodegradability improvement and consequently complete removal.
\end{abstract}

\section{Introduction}

Iodinated contrast media (ICM) are widely used in hospitals for urinary tract imaging. A large number of ICM are used in tests for patients ( $>100 \mathrm{~g}$ per dose), and the annual world-wide consumption of ICM was reported as approximately $3.5 \times 10^{6}$ kg. ${ }^{1}$ Due to their heavy use and high biochemical stability, increasing concentrations of ICM have been detected in hospital and domestic wastewater, treated wastewater effluent, surface water, groundwater, and even finished drinking water, whose concentration is up to $\mu \mathrm{g} \mathrm{L}^{-1} \cdot{ }^{2-6}$ Although ICM are believed to be harmless, subtle effects of mixtures of ICM with their metabolites and other micropollutants are unknown and may exert unanticipated ecological or human health risks. ${ }^{7}$

Due to high oxidation resistance of the tri-iodinated aromatic ring structure, ICM have been reported to only lose their alkyl side chains by biological and chemical oxidation. ${ }^{7}$ Alternatively, some reductive strategies have been developed for the removal of ICM from water, such as anaerobic biological

CAS Key Laboratory of Urban Pollutant Conversion, Collaborative Innovation Centre of Suzhou Nano Science and Technology, Department of Chemistry, University of Science and Technology of China, Hefei, China. E-mail: yangmu@ustc.edu.cn; Fax: +8655163607907

$\dagger$ Electronic supplementary information (ESI) available. See DOI: 10.1039/c7ra03750c transformation, ${ }^{8}$ dehalogenation through hydrogen with noble metal as the catalyst, and (bio)elelctrochemical reduction., However, there are some shortcomings in those methods. Anaerobic biodegradation needs high activity microbial species, and long processing time. Other chemical methods suffer from high cost, which inhibits their wide application. Therefore, it's urgent to find an efficient and low-cost technique for the treatment of ICM from water.

Zero-valent iron (ZVI) is an active metal whose electric potential is $-0.440 \mathrm{~V}$. Iron releases electrons when it is oxidized, making it be able to remove a variety of pollutants. ${ }^{10}$ It is noted that micro-scale ZVI powder has been successfully applied to treat iodine organic matters. ${ }^{\mathbf{1 1 - 1 3}}$ Compared to micro-scale ZVI, the nano-scale ZVI (nZVI) possesses greater surface activity to remove water pollutants effectively, ${ }^{\mathbf{1 4}}$ resulting from small particle size and sharp increase of specific surface area. Therefore, nZVI has been widely adopted to reductive removal of different pollutants such as chlorinated organic compounds, ${ }^{15,16}$ nitro-aromatic compounds, ${ }^{17,18}$ organic dyes ${ }^{19,20}$ and heavy metals. ${ }^{21,22}$ However, the utilization of nZVI to degrade ICM under anoxic conditions has seldom been investigated.

This study aimed at investigating the feasibility of nZVI for reductive dehalogenation of ICM from water, in which diatrizoate (DTA) was selected as the model ICM. The impacts of various parameters, including nZVI dosage, diatrizoate 
concentration, solution $\mathrm{pH}$, aging time of nZVI, the presence of natural organic matter (NOM), and type of competitive anions, on DTA dehalogenation using nZVI were evaluated. Furthermore, an aerobic post-treatment was conducted to study the biodegradability of reductive products of DTA dehalogenation using nZVI.

\section{Materials and methods}

\subsection{Materials}

Sodium diatrizoate ( $\geq 98 \%$ purity) and its reductive product 5diacetamidobenzoate (DABA, $\geq 98 \%$ purity) were purchased from Aladdin Industry Company (China) and Chem-Bridge Company (China), respectively. Humic acid was obtained from Sigma-Aldrich Company (Switzerland), and other chemicals including $\mathrm{NaBH}_{4}, \mathrm{FeCl}_{3}, \mathrm{NaCl}, \mathrm{NaNO}_{3}, \mathrm{Na}_{2} \mathrm{SO}_{4}, \mathrm{HCl}, \mathrm{NaOH}$, ethanol and riboflavin were purchased from Sinopharm Chemical Reagent Ltd (China). High purity of compressed $\mathrm{N}_{2}$ was obtained from Shangyuan Gas Products Co. (Nanjing, China). All the chemicals were used as receipt except for that humic acid was purified according to a previous method. ${ }^{23}$

\subsection{Synthesis and characterization of nZVI}

The nZVI particles were synthesized by using the liquid-phase reduction method. ${ }^{24}$ Briefly, $19.32 \mathrm{~g} \mathrm{FeCl}_{3} \cdot 6 \mathrm{H}_{2} \mathrm{O}$ was dissolved into $200 \mathrm{~mL} 30 \%$ ethanol solution, following with $\mathrm{N}_{2}$ purge for $20 \mathrm{~min}$. The reducing solution was prepared with $24.37 \mathrm{~g} \mathrm{NaBH}_{4}$ dissolved into $400 \mathrm{~mL}$ deionized water. After that, the reducing solution was added into the ferric solution on a mechanical stirrer with the speed of $300 \mathrm{rpm}$. The drop rate of reducing solution was controlled at 60-70 drops per min. The mixture was left to stir for another 30 min after the addition of $\mathrm{NaBH}_{4}$ solution was completed. Centrifugation was used to separate the liquid phase solution and the solid black particles. The solid black particles were washed three times with deionized water and ethanol, respectively, and then dried in a vacuum oven overnight at $65{ }^{\circ} \mathrm{C}$. The nZVI products were stored in an anaerobic operation box (Shellab, Bactron EZ, USA) containing $5 \% \mathrm{H}_{2}, 5 \% \mathrm{CO}_{2}$ and $90 \% \mathrm{~N}_{2}$ to avoid oxygen exposure.

The morphology of the synthesized nZVI nanoparticles (NPs) was examined using a transmission electron microscope (TEM) with a JED-2300T (JEM-2011, JEOL Ltd., Japan) and a ZEISS GEMINISEM 500 scan electron microscope (SEM) $($ EHT $=3.00$ $\mathrm{kV}, \mathrm{Mag}=30.00 \mathrm{k} \times, \mathrm{WD}=6.00 \mathrm{~mm}$, JSM-6700F, JEOL Ltd., Japan). The freshly prepared nZVI samples were dispersed in ethanol by ultrasonic before TEM and SEM tests. X-ray diffraction (XRD) analysis of nZVI particles was performed by using a Japan Rigaku TTR-III X-ray diffractometer at $40 \mathrm{kV}$ and $100 \mathrm{~mA}$ with a $\mathrm{Cu} \mathrm{K} \alpha(\lambda=1.54178)$ radiation source. Iron nanoparticles were scanned from $10^{\circ}$ to $80^{\circ}$ at $0.020^{\circ}$ per step and $8^{\circ} \mathrm{min}^{-1}$. Also, Fourier Transform Infrared (FTIR) spectrometer was used to examine the nZVI before and after the dehalogenation reaction (Nicolet 8700, Thermo Nicolet, USA).

\subsection{DTA dehalogenation experiments}

In the typical degradation experiments, $0.5 \mathrm{~mL}$ of $6 \mathrm{mM}$ DTA solution was added into a $150 \mathrm{~mL}$ serum bottle containing 100 $\mathrm{mL}$ deionized water with $\mathrm{pH}$ at 7.0, then was purged with nitrogen for $15 \mathrm{~min}$. Further, $0.05 \mathrm{~g}$ nZVI was added into the solution in the anaerobic operation box, and then the bottle was immediately sealed tightly with rubber stoppers and aluminum caps following with continuous shaking with $150 \mathrm{rpm}$ at $25^{\circ} \mathrm{C}$ for $120 \mathrm{~h}$ by using a bath shaker.

The effects of various parameters on DTA dehalogenation were investigated, including nZVI dosage, DTA concentration, $\mathrm{pH}, \mathrm{nZVI}$ aging time, the presence of NOM (riboflavin and humic acid), and competitive anions $\left(\mathrm{SO}_{4}{ }^{2-}, \mathrm{PO}_{4}{ }^{3-}\right.$ and $\left.\mathrm{NO}_{3}{ }^{-}\right)$. The experimental conditions are summarized in Table 1 . The initial solution $\mathrm{pH}$ was adjusted using $2 \mathrm{M} \mathrm{HCl}$ or $\mathrm{NaOH}$. Each experiment was carried out in duplicate.

\subsection{Aerobic post treatment}

An aerobic post-treatment was conduct at room temperature to test the biodegradable ability of the product from DTA dehalogenation in this study. After $96 \mathrm{~h}$ dehalogenation by nZVI with initial DTA concentration of $30 \mu \mathrm{M}$, the solution was collected and then centrifuged to prepare basal medium for aerobic biological treatment. The composition of basal medium was as follows ( $\mathrm{mg} \mathrm{L}^{-1}$ ): glucose 1880, $\left(\mathrm{NH}_{4}\right)_{2} \mathrm{SO}_{4} 2830, \mathrm{KH}_{2} \mathrm{PO}_{4} 132$, $\mathrm{K}_{2} \mathrm{HPO}_{4} \cdot 3 \mathrm{H}_{2} \mathrm{O} 221, \mathrm{CaCl}_{2} \cdot 2 \mathrm{H}_{2} \mathrm{O} 250, \quad \mathrm{FeSO}_{4} \cdot 7 \mathrm{H}_{2} \mathrm{O} 200$, $\mathrm{MgSO}_{4} \cdot 7 \mathrm{H}_{2} \mathrm{O} 200$ and $1.0 \mathrm{~mL}$ trace element solution. The trace element solution contained ( $\left.\mathrm{mg} \mathrm{L}^{-1}\right): \mathrm{H}_{3} \mathrm{BO}_{3} 50, \mathrm{ZnCl}_{2} 50$, $\mathrm{CuCl}_{2} \cdot 2 \mathrm{H}_{2} \mathrm{O} 30, \mathrm{MnSO}_{4} \cdot \mathrm{H}_{2} \mathrm{O} 50, \mathrm{Na}_{2} \mathrm{Mo}_{7} \mathrm{O}_{4} \cdot 2 \mathrm{H}_{2} \mathrm{O} 60, \mathrm{AlCl}_{3} 50$, $\mathrm{CoCl}_{2} \cdot 6 \mathrm{H}_{2} \mathrm{O} 50$, and $\mathrm{NiCl}_{2} \cdot 6 \mathrm{H}_{2} \mathrm{O} 50 .^{25} 2 \mathrm{~g} \mathrm{~L}^{-1} \mathrm{NaHCO}_{3}$ was added as buffer solution. $10 \mathrm{~g}$ VSS per L (VSS: volatile total solids) of aerobic sludge from Wangtang municipal wastewater treatment plant (Hefei, China) was inoculated into a $440 \mathrm{~mL}$ serum bottle with basal medium to a final working volume of $250 \mathrm{~mL}$. To exclude the possibility of sludge adsorption, the control experiments were conducted without oxygen. A pump was used to purge air into the solution to guarantee adequate oxygen during experiments. The dissolved oxygen (DO) in the solution was monitored with LDO101 dissolved oxygen probe (HACH, USA). Additionally, experiments with $30 \mu \mathrm{M}$ DTA in the basal medium were also conducted to investigate whether DTA could be degraded by the aerobic activated sludge. Each experiment was repeated twice.

\subsection{Analysis and calculations}

Samples were collected at selected time intervals by syringes and then filtered through a $0.45 \mu \mathrm{m}$ membrane for further analysis. The concentrations of DTA and DABA were analyzed using high performance liquid chromatography (Agilent 1260, USA) with an Agilent HC-C18 column $(5 \mu \mathrm{m}, 4.6 \mathrm{~mm} \times 250$ $\mathrm{mm})$. The mobile phase was a mixture of $0.1 \%$ formic acidmethanol $(75: 25, \mathrm{v} / \mathrm{v})$ with flow rate of $1.0 \mathrm{~mL} \mathrm{~min}{ }^{-1}$ and the UV detector was set at $254 \mathrm{~nm}$. Samples after $24 \mathrm{~h}$ dehalogenation reaction in the typical experiments were collected for the identification of intermediate products using liquid 
Table 1 Summary of operational conditions for different experiments

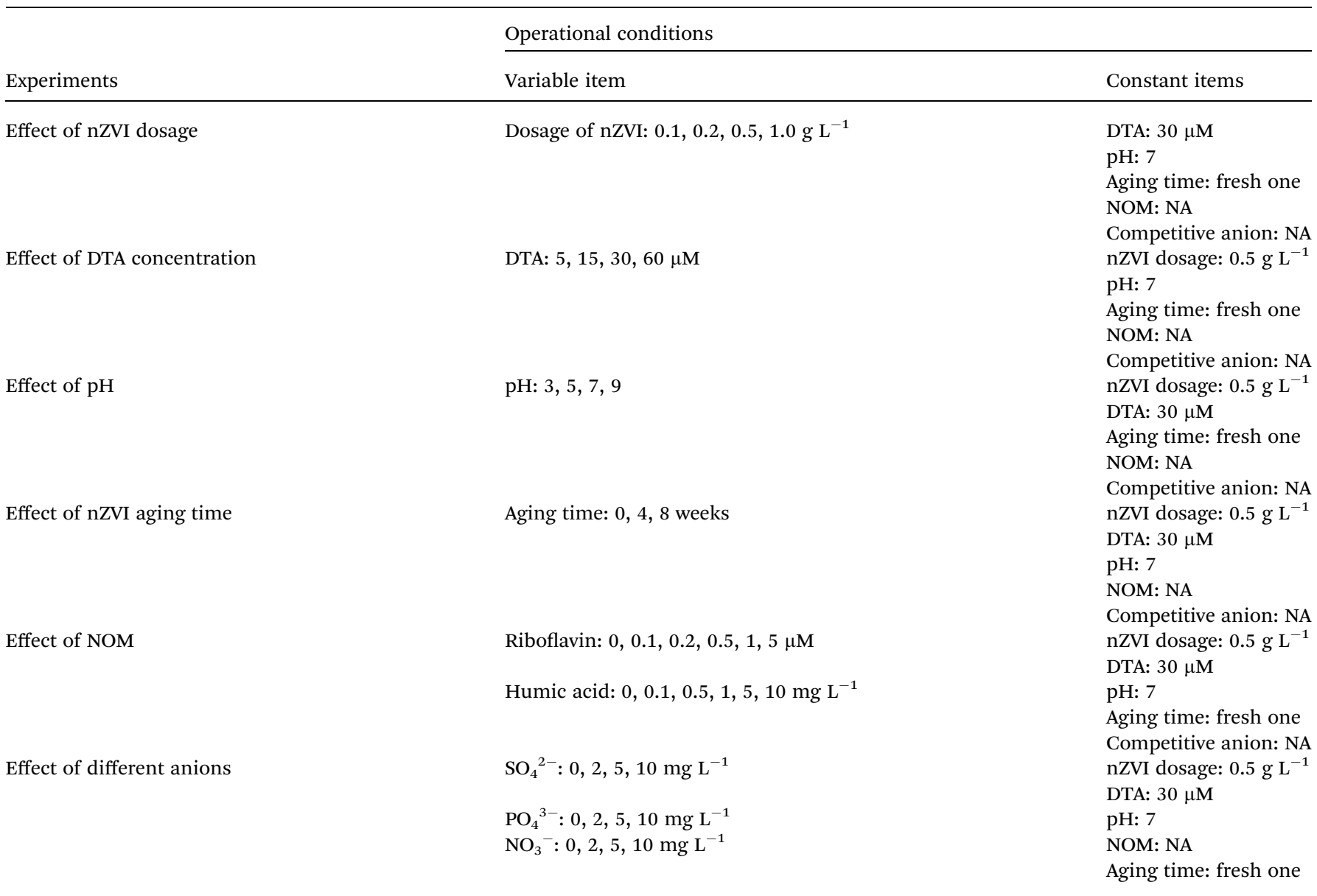

chromatography electrospray ionisation tandem mass spectrometry (LC-ESI-MS) (LTQ-Orbitrap XL, ThermoFisher Co., USA), in which the chromatographic conditions are as same as those for DTA and DABA analysis, and other parameters are summarized in Table S1 of the ESI. $\dagger$ The concentrations of $\mathrm{SO}_{4}{ }^{2-}$ and $\mathrm{PO}_{4}{ }^{3-}$ were determined by ion chromatography (DIONEX ICS-1100, USA) equipped with an AS19 column and an electrical conductivity detector. The $\mathrm{KOH}$ effluent was used as mobile phase with concentration gradient ranging from 10 to $40 \mathrm{mM}$ and 25 to $65 \mathrm{mM}$ at $1 \mathrm{~mL} \mathrm{~min}{ }^{-1}$, respectively. $\mathrm{I}^{-}$ concentration was analyzed by using UV-vis spectrophotometer (Agilent Cary 60, USA) at $226 \mathrm{~nm},{ }^{26}$ while $\mathrm{Fe}^{2+}$ concentration was determined with phenanthroline method at $510 \mathrm{~nm} \cdot{ }^{27}$ The concentrations of $\mathrm{NO}_{3}{ }^{-}$and $\mathrm{NH}_{4}{ }^{+}$were measured with UV-vis spectrophotometer (Agilent Cary 60, USA) at 220 and $697 \mathrm{~nm}$ by coordinating with salicylic acid and hypochlorous acid, respectively. ${ }^{27}$

The DTA removal efficiency (DRE, \%) and the DABA formation efficiency (DFE, \%) at time $t(\mathrm{~h})$ were determined using the following equations:

$$
\begin{gathered}
\mathrm{DRE}=\left(C_{\mathrm{DTA}, 0}-C_{\mathrm{DTA}, t}\right) / C_{\mathrm{DTA}, 0} \times 100 \\
\mathrm{DFE}=C_{\mathrm{DABA}, \ell} / C_{\mathrm{DTA}, 0} \times 100
\end{gathered}
$$

where $C_{\mathrm{DTA}, 0}(\mu \mathrm{M})$ is the initial DTA concentration, $C_{\mathrm{DTA}, t}(\mu \mathrm{M})$ is the DTA concentration at reaction time $t(\mathrm{~h})$, and $C_{\mathrm{DABA}, t}(\mu \mathrm{M})$ is the DABA concentration at reaction time $t$.

\section{Results and discussion}

\subsection{Typical DTA dehalogenation with nZVI}

As shown in Fig. 1a, nZVI particles prepared in our study had a chain-like, core-shell structure and were nearly spherical with a size around $50 \mathrm{~nm},{ }^{28}$ which was also demonstrated by the SEM image (Fig. 1b). The peak at $44.67^{\circ}$ in Fig. 1c confirmed that $\mathrm{Fe}^{0}$ was the majority of the particle component. ${ }^{28} \mathrm{Fig}$. 2a illustrates the trend in concentrations of DTA, DABA and $\mathrm{I}^{-}$over time in typical DTA dehalogenation experiments using nZVI particles. Dosing with $0.5 \mathrm{~g} \mathrm{~L}^{-1} \mathrm{nZVI}$ particles resulted in a rapid decrease of DTA concentration and a corresponding rise of the concentrations of DABA and $\mathrm{I}^{-}$. The DTA removal efficiency reached to $100 \%$ within $24 \mathrm{~h}$, while the DABA formation efficiency was only $39.6 \%$ in 24 and it reached to $84.0 \%$ after $120 \mathrm{~h}$ reaction. In addition, it should be mentioned that DABA concentration still slowly increased with reaction time after DTA was completely removed (Fig. 2a). Moreover, the adsorption of DABA on nZVI was negligible, as shown in Fig. S3. $\dagger$ These results indicate that DTA dehalogenation by nZVI was fast while the DABA formation was the limiting step reaction. Therefore, we speculate that all 

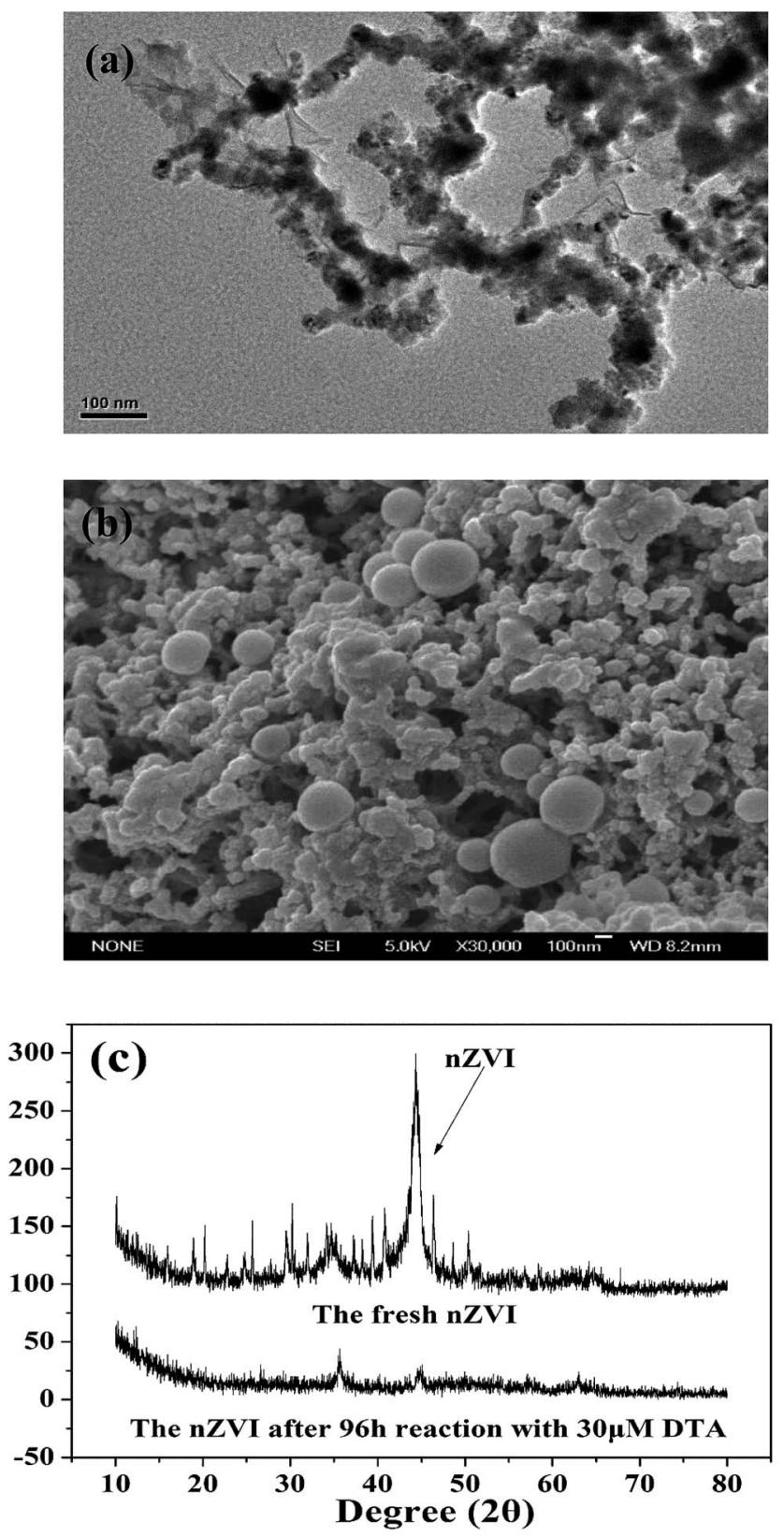

Fig. 1 Images of the synthesized nZVI particles: (a) TEM, (b) SEM and (c) XRD.

DTA could be completely reduced to DABA by nZVI but with much long reaction time at high pHs.

As illustrated in Fig. $2 \mathrm{~b}$, the reaction $\mathrm{pH}$ increased rapidly from 7.0 to 9.4 within $2 \mathrm{~h}$ because of the reaction between nZVI and $\mathrm{H}_{2} \mathrm{O}$ or DTA with proton consumption. ${ }^{11}$ After that, the solution $\mathrm{pH}$ changed slightly, properly due to the equilibrium for the $\mathrm{Fe}(\mathrm{OH})_{2} / \mathrm{H}_{2} \mathrm{O}$ system $(\mathrm{pH}=8.9) .{ }^{29} \mathrm{Fig}$. $1 \mathrm{c}$ shows that the crystal form of nZVI was totally destroyed after $96 \mathrm{~h}$ dehalogenation reaction. The nZVI surface passivation under high $\mathrm{pH}$ occurs easily, while DTA removal and DABA formation were continuous after $2 \mathrm{~h}$ in this study. Additionally, we also tested the reductive ability of $\mathrm{Fe}^{2+}$ and found that DTA concentration changed slightly regardless of $\mathrm{Fe}^{2+}$ concentration (Fig. 2c).
Thus, the possible contribution to DTA removal and DABA formation in this study may partially result from surface-bound $\mathrm{Fe}^{2+}$ and/or other reactive corrosion products like green rust. Several studies have reported that the green rust could dechlorinate different pollutants effectively. ${ }^{30,31}$ Erbs et al. found that green rusts formed during corrosion of ZVI under nonacid conditions may considerably contribute to the total reduction of $\mathrm{CCl}_{4} \cdot{ }^{30}$ Satapanajaru et al. reported that the green rusts provided a source of $\mathrm{Fe}(\mathrm{II})$ and produced magnetite (and other oxide surfaces) that coordinated $\mathrm{Fe}(\mathrm{II})$, which then facilitated dechlorination. ${ }^{31}$

As shown in Fig. 2a, $\mathrm{I}^{-}$concentration increased from 0 to $77.46 \mu \mathrm{M}$ within $96 \mathrm{~h}$ due to the dehalogenation of DTA in the typical experiments. Based on the mass balance calculation, the total detectable iodine concentration (i.e., $\mathrm{I}^{-}$concentration +3 $\left.\times C_{\mathrm{DTA}, t}\right)$ decreased from 90 to $53.78 \mu \mathrm{M}$ and then increased to $77.46 \mu \mathrm{M}$ during reaction (Fig. 2d). The missing iodine was speculated to exist in the intermediate products with one or two iodine loss during DTA dehalogenation. ${ }^{8}$ The results from LCESI-MS analysis confirmed the formation of intermediate products (DTA-2I, DTA-I) during DTA dehalogenation process, as shown in Fig. S1 and S2.† Since each DTA dehalogenation experiment was carried out under anaerobic conditions, it could be concluded that reductive transformation was majorly happened during DTA dehalogenation by nZVI in this study. The oxidative Fenton like reaction for DTA degradation would be negligible because this reaction need an aerobic condition. Recently, Stieber et al. investigated ICM removal by granular ZVI with a particle size of $0.125-3.000 \mathrm{~mm}$ in the presence of oxygen at acidic pH conditions, ${ }^{11}$ and DTA only reduced by $60 \%$ in $8 \mathrm{~h}$, indicating a slower removal rate compared to our study. Besides for reductive transformation by ZVI, they found that oxidative process were also responsible for the removal of ICM, which is due to the formation of hydrogen peroxide as an intermediate product for the oxidation of ZVI in aerobic water.

\subsection{Effects of various parameters}

3.2.1 nZVI dosage. The effect of nZVI dosage on DTA dehalogenation is shown in Fig. 3a and b. DTA was completely degraded in $24 \mathrm{~h}$ at different nZVI dosages, but both the removal rate and efficiency of DTA were merely affected by the dosage of nZVI in a range of $0.1-1.0 \mathrm{~g} \mathrm{~L}^{-1}$ (Fig. 3a). The DABA formation efficiency at $48 \mathrm{~h}$ was increased from $40.3 \%$ to $73.7 \%$ when nZVI dosage was increased from 0.1 to $0.5 \mathrm{~g} \mathrm{~L}^{-1}$, and then changed slightly with the further increase to $1.0 \mathrm{~g} \mathrm{~L}^{-1}$ (Fig. 3b). These results further imply that DTA dehalogenation was fast by nZVI while DABA formation was the rate-limiting step. However, Li et al. found that higher nZVI dose resulted in the higher $\mathrm{Cr}(\mathrm{vI})$ reduction rate for $\mathrm{Cr}(\mathrm{VI})$ immobilization using nZVI particles. ${ }^{32}$

3.2.2 DTA concentration. The removal of DTA with nZVI as a function of initial DTA concentration was examined in the range of 5-60 $\mu \mathrm{M}$. The DTA could be degrade completely within $36 \mathrm{~h}$ in all batch experiments, while the amount of dehalogenated DTA increased with the increase in initial DTA concentration (Fig. 3c). Meanwhile, the amount of DABA generated increased with the increase in initial concentration of 

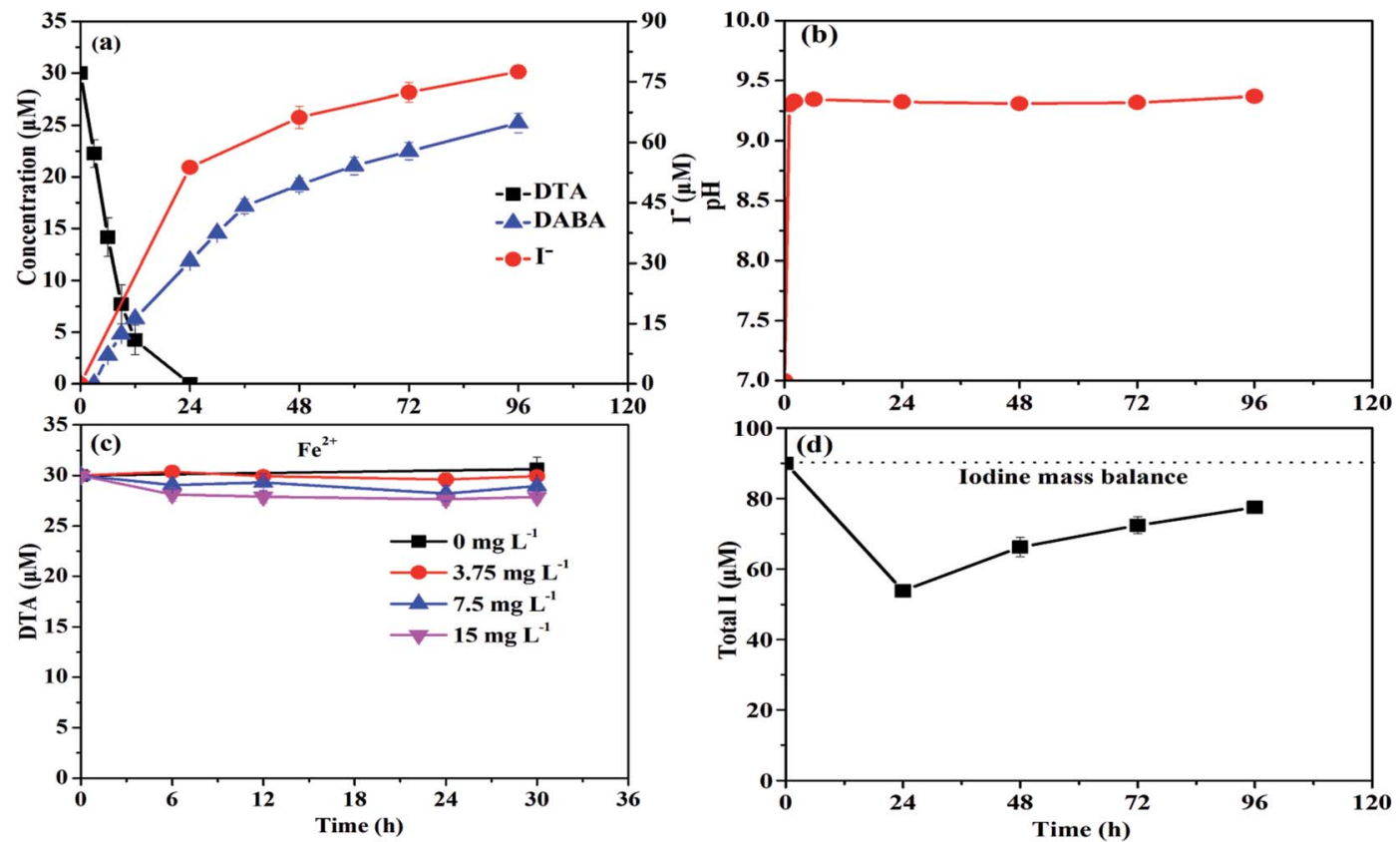

Fig. 2 Variations of (a) DTA removal, DABA formation and $\mathrm{I}^{-}$release, (b) $\mathrm{pH}$ as a function of reaction time in typical dehalogenation experiments (30 $\mu \mathrm{M}$ DTA, $0.5 \mathrm{~g} \mathrm{~L}^{-1} \mathrm{nZVI}$, and $\mathrm{pH}$ at 7), and (c) DTA removal by Fe $\mathrm{Fe}^{2+}$ at various concentrations, and (d) the total detectable I.

DTA, but the DABA formation efficiency was similar under different initial DTA concentrations, which reached to nearly $80 \%$ after $120 \mathrm{~h}$ reaction (Fig. $3 \mathrm{~d}$ ). A similar phenomenon was also observed for tetracycline removal using polyvinylpyrrolidone modified nZVI, where the amount of tetracycline removed increased with the improvement of initial tetracycline concentration. ${ }^{33}$

3.2.3 $\mathrm{pH}$. The removal of DTA as well as the generation of DABA was investigated as a function of initial solution $\mathrm{pH}$ from 3.0 to 9.0. As shown in Fig. 4a and b, solution pH had a significant impact on both the removal of DTA and the formation of
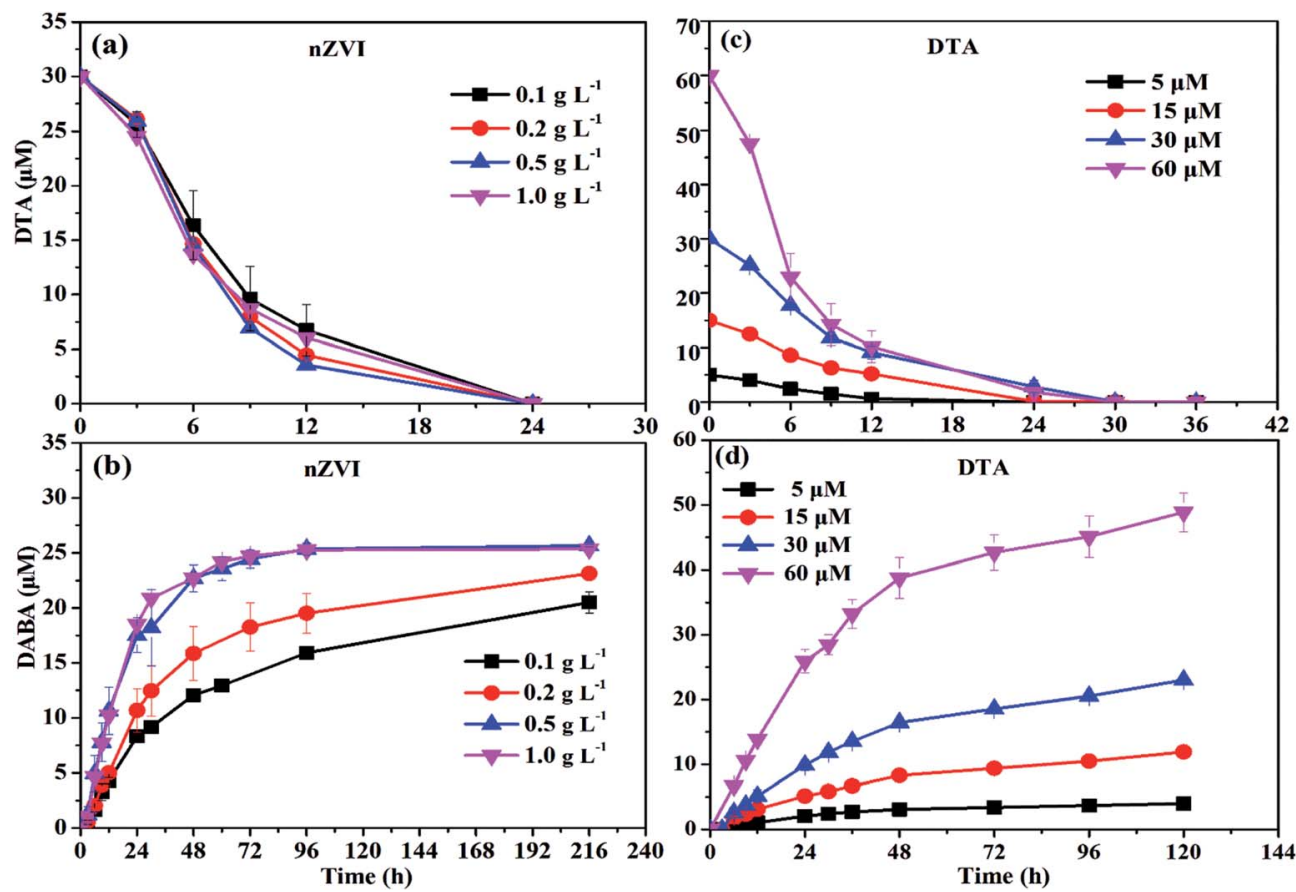

Fig. 3 Effect of nZVI dosage on (a) DTA removal and (b) DABA formation, and effect of DTA concentration on (c) DTA removal and (d) DABA formation. 

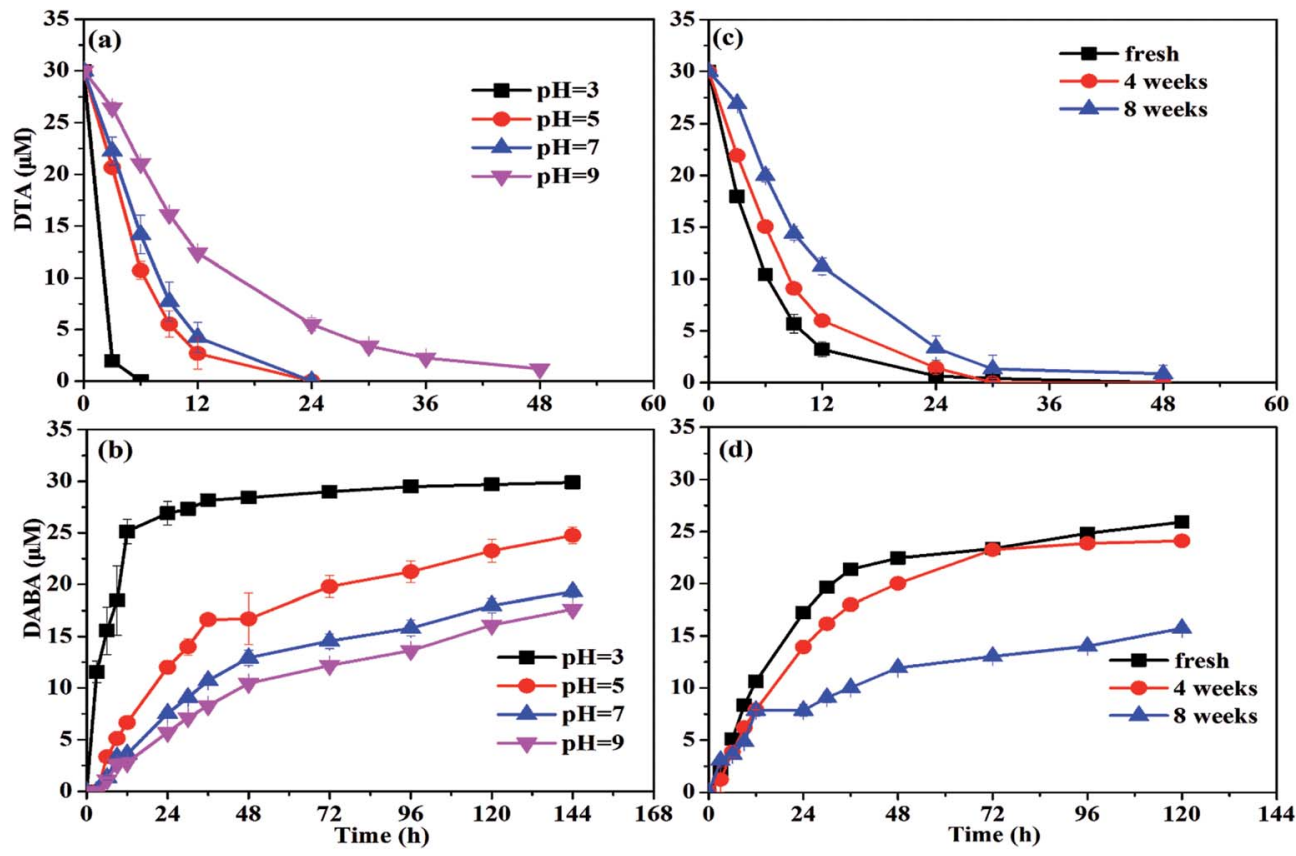

Fig. 4 Effect of $\mathrm{pH}$ on (a) DTA removal and (b) DABA formation, and effect of nZVI aging time on (c) DTA removal and (d) DABA formation.

DABA. When initial pH was increased from 3.0 to 9.0, the DTA removal efficiency at $9 \mathrm{~h}$ was reduced from $100 \%$ to $46.3 \%$, and simultaneously the DABA formation efficiency at $24 \mathrm{~h}$ was decreased from $89.7 \%$ to $19.0 \%$. pH is well known to affect rates of reactions with ZVI due to effects on iron corrosion, producing more corrosion at lower $\mathrm{pH}$ values and more passivation by mineral precipitation at higher $\mathrm{pH}$ values. ${ }^{34}$ We found that the solution $\mathrm{pH}$ rapidly changed from 3.0, 5.0, 7.0 and 9.0 to 6.4, 7.5, 9.4 and 9.5, respectively, and then kept constantly.
Therefore, the deterioration of DTA removal as well as DABA generation at higher pHs could be attributed to the fact that the precipitation generated and wrapped the nZVI to inhibit the contact between NZVI and DTA.

3.2.4 nZVI aging time. The aggregation and shell transformation of nZVI particles with time could affect their reactivity and longevity. ${ }^{29}$ Compared with fresh nZVI, the DTA removal efficiency at $12 \mathrm{~h}$ was decreased from $89.0 \%$ to $80.0 \%$ and $62.6 \%$ using nZVI with aging time at 4 and 8 weeks,
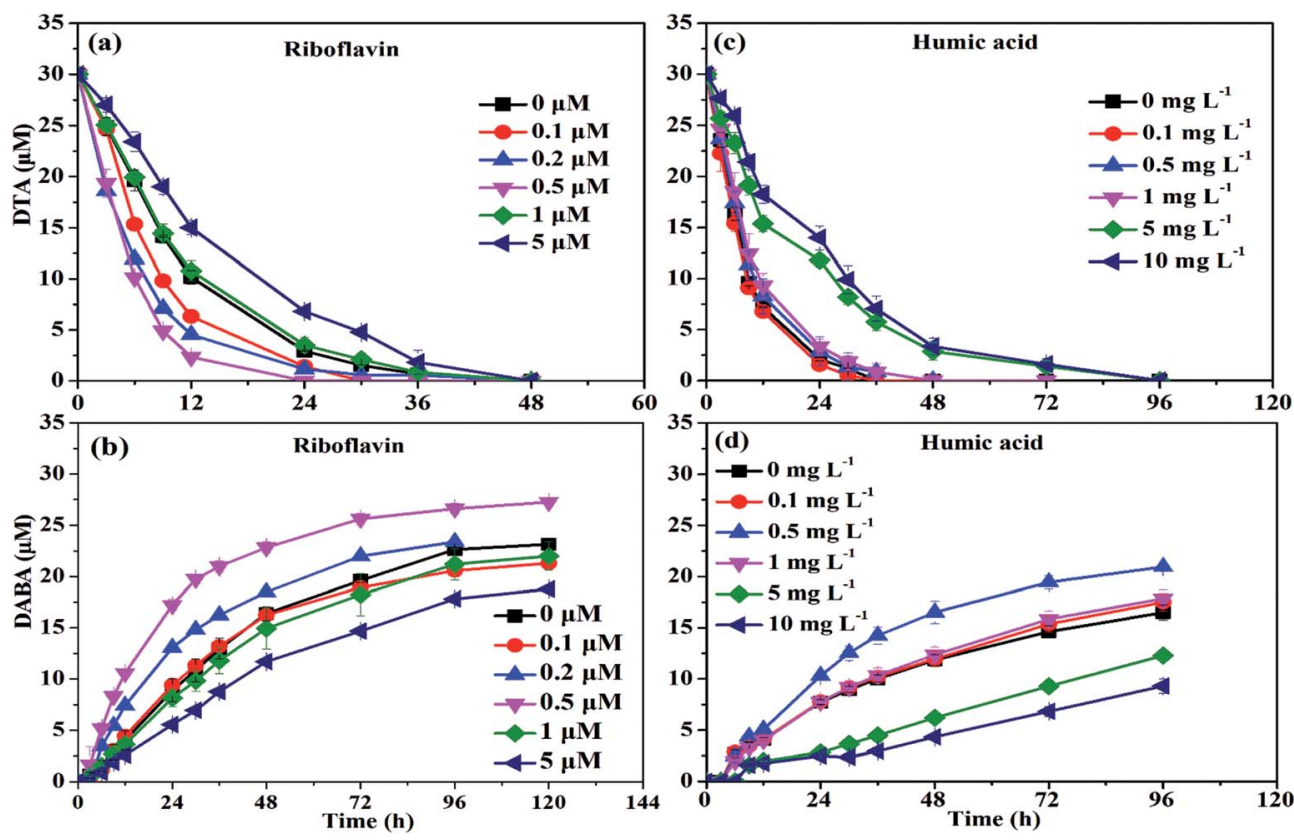

Fig. 5 DTA dehalogenation with nZVI in the presence of two different NOMs. 


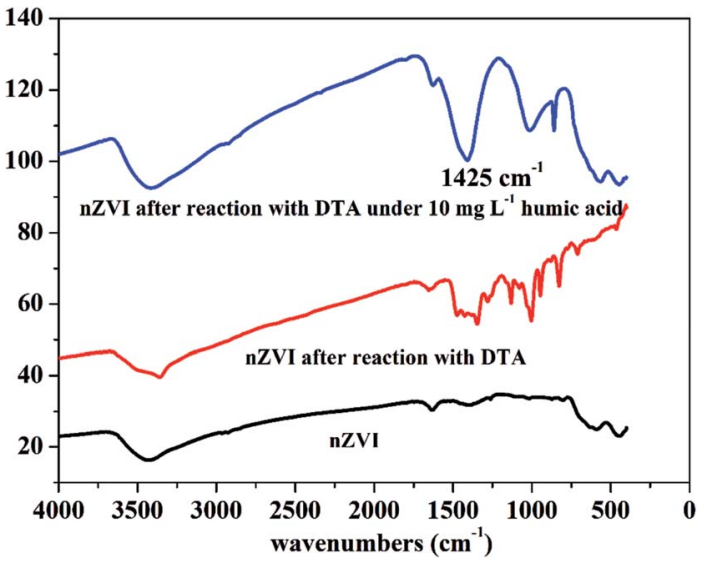

Fig. 6 FTIR images of nZVI before and after dehalogenation reaction in the presence or absence of humic acid.

respectively (Fig. 4c). Meanwhile, the DABA formation efficiency at $24 \mathrm{~h}$ was significantly reduced to $26.1 \%$ using nZVI with aging time at 8 weeks (Fig. 4d). We did not find the remarkable aggregation of nZVI particles with different aging times in this study. It was reported that the nZVI could transform into iron oxide particulates like $\mathrm{FeO},{ }^{35} \mathrm{FeOOH},{ }^{36} \gamma-\mathrm{Fe}_{2} \mathrm{O}_{3}$ and $\mathrm{Fe}_{3} \mathrm{O}_{4}{ }^{37}$ to form the oxide shell on the surface of nZVI during aging and moreover the oxide shell increased with increasing aging time. ${ }^{29}$ This might prevent the contact between nZVI and DTA and thus result in the poor dehalogenation performance.

To activate the aged nZVI and recover its reactivity, several methods can be effective, such as acid washing, $\mathrm{H}_{2^{-}}$ pretreatment and ultrasound. After acid washing, the oxide layer on the surface of nZVI is able to be dissolved into solution and transformed into $\mathrm{Fe}^{2+}$ or $\mathrm{Fe}^{3+}$. It involves the reconversion of oxidized iron compounds to iron chlorides, which can participate again as a precursor in a regenerating synthesis process with $\mathrm{NaBH}_{4}$ reductant to produce nZVI. ${ }^{38}$ The $\mathrm{H}_{2}$ pretreatment method offered several advantages over the acidwashing method practically without wastewater or sludge generation. Liou et al. employed hydrogen gas at $400{ }^{\circ} \mathrm{C}$ to activate the ZVI surface to improve nitrate removal by ZVI and they found that the lag period of nitrate removal by $\mathrm{H}_{2}$-pretreated ZVI disappeared and the first-order reaction rate constant was increased by 4.7 times compared with the nonpretreated ZVI. ${ }^{39}$ The ultrasound method serves to increase the active iron surface, improve reaction rates, and increase the concentration of terminal by-products. Geiger $e t$ al. showed the kinetic improvement caused by ultra-sound pretreatment and illustrated that ultrasound could clear the iron surfaces of debris and thus increase the surface area up to $169 \%{ }^{40}$

3.2.5 The presence of NOM. NOM, widespread in the environment where nZVI technologies are most applicable, is an important factor for controlling the degradation of contaminants. ${ }^{41}$ The effect of two common NOMs, i.e., riboflavin and humic acid, on DTA removal with nZVI was evaluated in this study. As shown in Fig. 5, both of them showed a similar consequence for DTA dehalogenation. The rates of both DTA removal and DABA generation increased as riboflavin concentration was increased from 0 to $0.5 \mu \mathrm{M}$, while they reduced when riboflavin concentration further increased from 0.5 to $5 \mu \mathrm{M}$. Similarly, the DABA formation efficiency increased from $55.0 \%$
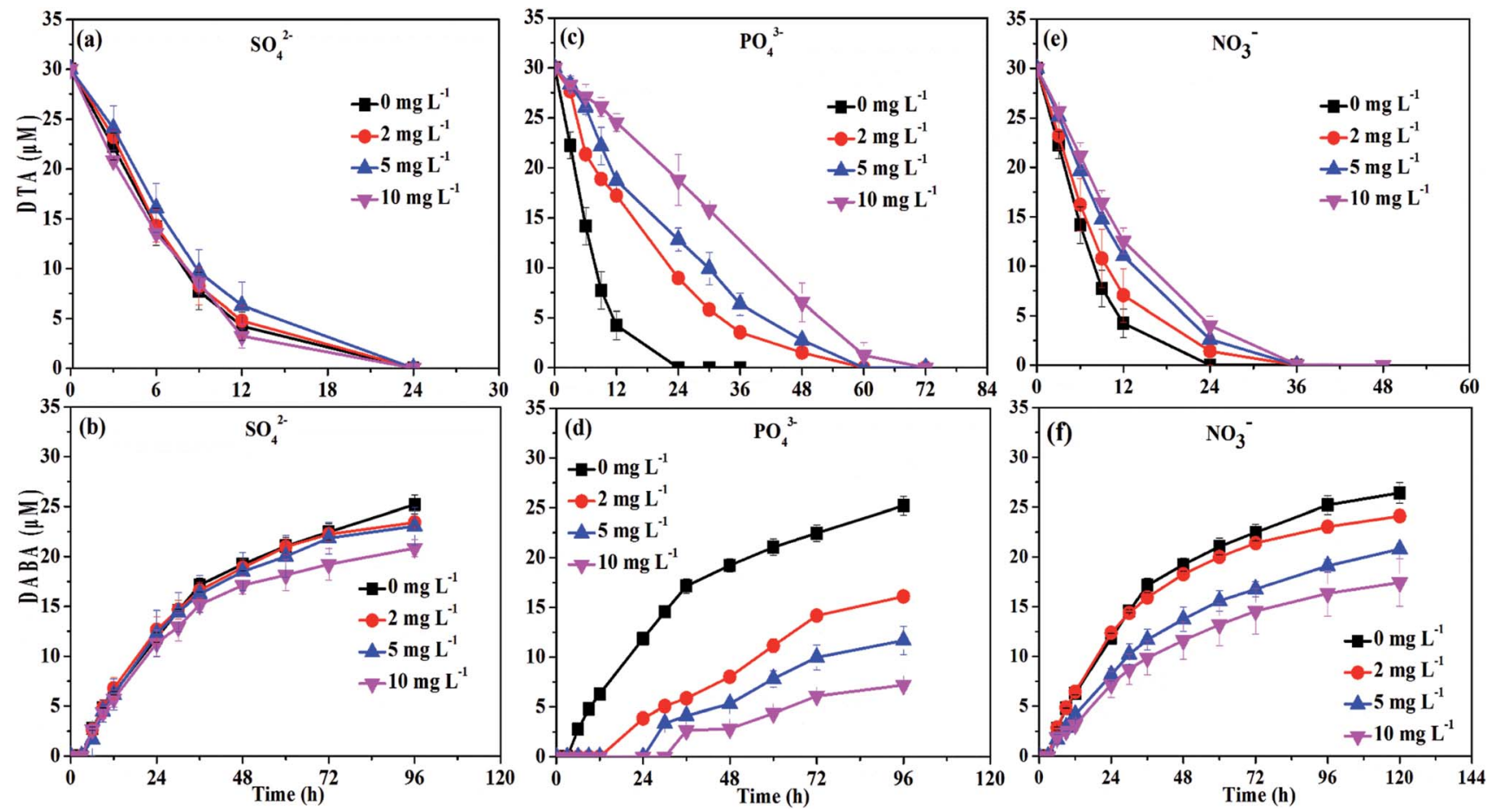

Fig. 7 DTA dehalogenation with $\mathrm{nZVI}$ in the presence of different anions $\left(\mathrm{SO}_{4}{ }^{2-}, \mathrm{PO}_{4}{ }^{3-}\right.$, and $\left.\mathrm{NO}_{3}{ }^{-}\right)$. 

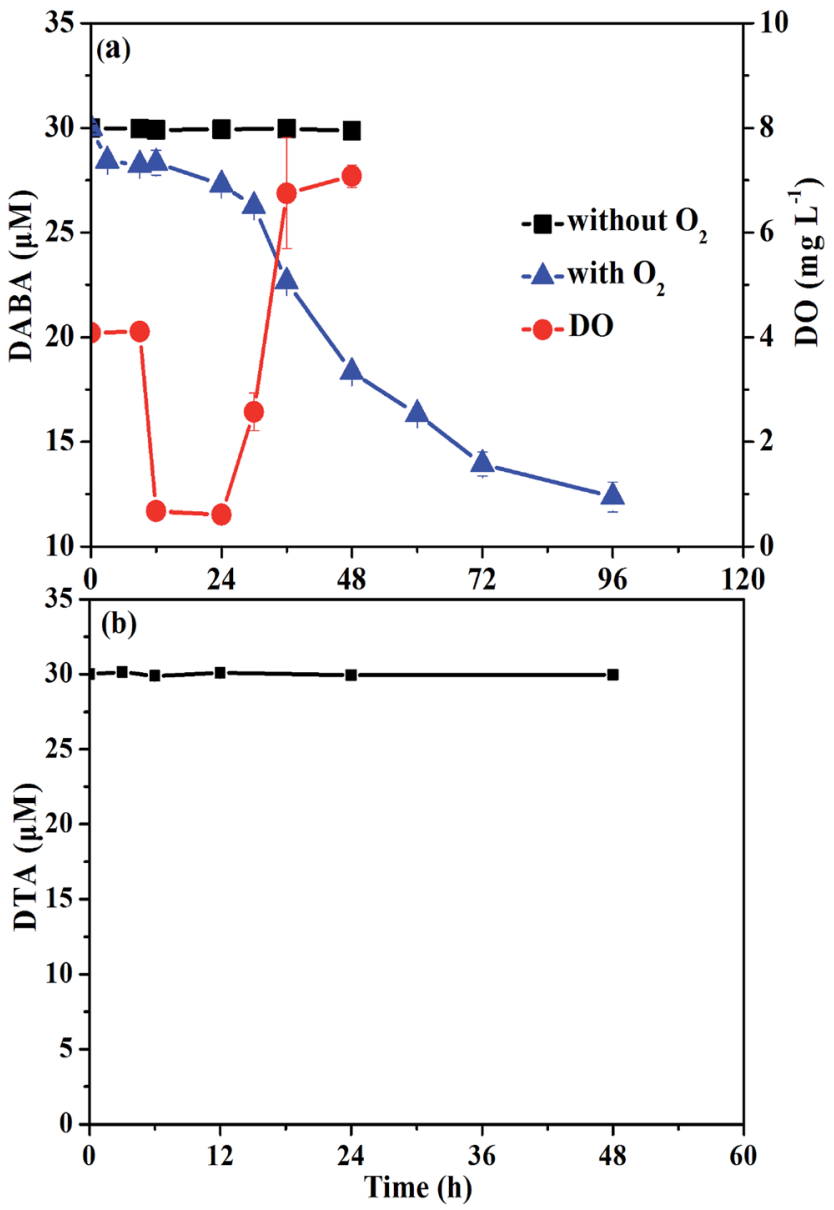

Fig. 8 Concentration changes of DTA, DABA and DO during aerobic biological post-treatment.

to $69.8 \%$ after $96 \mathrm{~h}$ when the concentration of humic acid was increased from 0 to $0.5 \mathrm{mg} \mathrm{L}^{-1}$, and then reduced to $31.0 \%$ with a further increase in humic acid concentration to $10 \mathrm{mg} \mathrm{L}^{-1}$ (Fig. 5d).

At low concentrations, several studies have found that NOM was able to act as the electron shuttle to rapidly transfer electrons, leading to enhanced reductive degradation of contaminants. ${ }^{42}$ For instance, Kim et al. observed that the degradation rate of $\mathrm{NO}_{3}{ }^{-}$by nZVI was accelerated in the presence of 6.25$100 \mathrm{mg} \mathrm{L}^{-1}$ humic acid, and they suggested that quinone moieties (e.g., p-hydroquinone, lawsone, and 9,10anthraquinone-2,6-disulfonate (AQDS)) in humic acid played a pivotal role in enhancing degradation of $\mathrm{NO}_{3}{ }^{-}$by nZVI. ${ }^{42}$ On the contrary, in the presence of high concentration of NOM, adsorption of NOM onto reaction sites on the surface of iron phases would play a major role in inhibiting the reductive degradation of pollutants by nZVI. Adsorption of NOM can compete with contaminants in ways which can decelerate the kinetics of contaminant degradation. ${ }^{42,43}$ The FTIR images further proved this phenomenon. As shown in Fig. 6, a characteristic peak at $1425 \mathrm{~cm}^{-1}$, belongs to $-\mathrm{CH}$ deformation of $-\mathrm{CH}_{3}$ and $-\mathrm{CH}$ bending of $\mathrm{CH}_{2}$ (ref. 44), was found in the presence of
$10 \mathrm{mg} \mathrm{\textrm {L } ^ { - 1 }}$ humic acid, strongly suggesting the adsorption of humic acid on the surface of nZVI. ${ }^{36}$

3.2.6 Competitive anions. The effects of different anions $\left(\mathrm{SO}_{4}{ }^{2-}, \mathrm{PO}_{4}{ }^{3-}\right.$ and $\left.\mathrm{NO}_{3}{ }^{-}\right)$on DTA dehalogenation using nZVI are shown in Fig. 7. Sulfate had an insignificant influence on DTA dehalogenation in terms of DTA removal and DABA formation (Fig. 7a and b), while both $\mathrm{PO}_{4}{ }^{3-}$ and $\mathrm{NO}_{3}{ }^{-}$showed passive impacts.

The DTA removal efficiency at $24 \mathrm{~h}$ reduced from $100 \%$ to $37.4 \%$ when $\mathrm{PO}_{4}{ }^{3-}$ concentration was improved from 0 to $10 \mathrm{mg}$ $\mathrm{L}^{-1}$, and at the same time the DABA formation efficiency at $48 \mathrm{~h}$ decreased from $64.1 \%$ to 9 . $4 \%$ (Fig. $7 \mathrm{c}$ and d). The negative effect might be due to that $\mathrm{PO}_{4}{ }^{3-}$ is an inner-sphere complexforming anion which could strongly sorb to mineral surfaces, thus hindering the sorption of DTA on the surface of nZVI particles. Indeed, we found that the $\mathrm{PO}_{4}{ }^{3-}$ in the solution completely disappeared after reaction. The disappearance of $\mathrm{PO}_{4}{ }^{3-}$ may result from precipitation with ferrous ion or coprecipitation with $\mathrm{Fe}(\mathrm{OH})_{2}$ due to high $\mathrm{pH} .{ }^{45}$ Chen et al. also observed that $\mathrm{PO}_{4}{ }^{3-}$ had a negative effect on the removal of tetracycline with polyvinylpyrrolidone modified nZVI. ${ }^{33}$

Similarly, the rates of both DTA removal and DABA formation reduced when concentration of $\mathrm{NO}_{3}{ }^{-}$were increased from 0 to $10 \mathrm{mg} \mathrm{L}^{-1}$ (Fig. 7e and f). As shown in Fig. $\mathrm{S} 4, \dagger \mathrm{NO}_{3}{ }^{-}$was completely transformed into $\mathrm{NH}_{4}^{+}$by nZVI after $24 \mathrm{~h}$ reaction with initial $\mathrm{NO}_{3}{ }^{-}$concentration of $10 \mathrm{mg} \mathrm{L}^{-1}$, and the removal efficiency at $12 \mathrm{~h}$ reached to $87.4 \%$, suggesting that $\mathrm{NO}_{3}{ }^{-}$ removal was faster than DTA reduction by nZVI. This implies that that $\mathrm{NO}_{3}{ }^{-}$was able to compete with DTA for reactive sites and electrons of the nZVI, resulting in inhibition of DTA dehalogenation. Meanwhile, the reaction between $\mathrm{NO}_{3}{ }^{-}$and nZVI could make the oxide-shell thicker, and the surface passivation become more seriously with the concentration of $\mathrm{NO}_{3}{ }^{-}$increased. ${ }^{46}$

\subsection{Performance of aerobic biological post-treatment}

To test the biodegradability of reductive products of DTA dehalogenation using nZVI, aerobic biological post-treatment was conducted in this study. We first excluded the volatilization possibility of DABA even with $\mathrm{O}_{2}$ supply (data not shown). As shown in Fig. 8, DABA concentration was unchanged without $\mathrm{O}_{2}$ supply, suggesting insignificant adsorption of DABA onto sludge. In the presence of oxygen, the DABA removal efficiency was $58.8 \%$ after $96 \mathrm{~h}$, indicating that aerobic sludge had a good degradation ability on DABA. The other transformation products including DTA-2I and DTA-I, which are present with much low concentrations, were not examined during aerobic degradation experiments. Meanwhile, the DO concentration declined in first $8 \mathrm{~h}$ and then increased to around $8 \mathrm{mg} \mathrm{L}^{-1}$, majorly due to the consumption of glucose in the solution. In addition, we also found that DTA couldn't be degraded by aerobic biological treatment (Fig. 8b). These results illustrated that DTA dehalogenation with nZVI would be a vital procedure for its biodegradability improvement and consequently complete removal. 


\section{Conclusions}

The present study demonstrated that the nZVI could be effectively adopted for the dehalogenation of DTA. The DTA removal efficiency reached to $100 \%$ within $24 \mathrm{~h}$ in typical experiments with $0.5 \mathrm{~g} \mathrm{~L}^{-1} \mathrm{nZVI}$ particles. DTA dehalogenation in terms of its removal and DABA formation was enhanced with the increase in nZVI dosage but deteriorated when increasing solution $\mathrm{pH}$. nZVI aging time had a negative impact on DTA dehalogenation. The presence of NOM at much low level could improve DTA dehalogenation, while negatively affected DTA removal at high concentrations. Contrary to sulfate, both nitrate and phosphate ions strongly inhibited DTA removal with nZVI. The results also showed that DABA could be degraded by aerobic biological posttreatment, suggesting DTA dehalogenation with nZVI may be a vital procedure for its biodegradability improvement and consequently complete removal.

\section{Acknowledgements}

The authors wish to thank the Natural Science Foundation of China (51538012 and 51478446), the Recruitment Program of Global Experts, and the Fundamental Research Funds for the Central Universities for financially supporting this study.

\section{References}

1 S. Perez and D. Barcelo, Anal. Bioanal. Chem., 2007, 387, 1235-1246.

2 T. A. Ternes and R. Hirsch, Environ. Sci. Technol., 2000, 34, 2741-2748.

3 S. Echeverria, F. Borrull, N. Fontanals and E. Pocurull, Talanta, 2013, 116, 931-936.

4 A. Putschew, S. Schittko and M. Jekel, J. Chromatogr. A, 2001, 930, 127-134.

5 A. Putschew, S. Wischnack and M. Jekel, Sci. Total Environ., 2000, 255, 129-134.

6 F. Sacher, B. Raue and H. H. Brauch, J. Chromatogr. A, 2005, 1085, 117-123.

7 Y. Mu, J. Radjenovic, J. Y. Shen, R. A. Rozendal, K. Rabaey and J. Keller, Environ. Sci. Technol., 2011, 45, 782-788.

8 M. Redeker, A. Wick, B. Meermann and T. A. Ternes, Environ. Sci. Technol., 2014, 48, 10145-10154.

9 C. Zwiener, T. Glauner, J. Sturm, M. Worner and F. H. Frimmel, Anal. Bioanal. Chem., 2009, 395, 1885-1892.

10 F. L. Fu, D. D. Dionysiou and H. Liu, J. Hazard. Mater., 2014, 267, 194-205.

11 M. Stieber, A. Putschew and M. Jekel, Environ. Sci. Technol., 2011, 45, 4944-4950.

12 M. Stieber, A. Putschew and M. Jekel, Water Sci. Technol., 2008, 57, 1969-1975.

13 A. Putschew, U. Mlehe, A. S. Tellez and M. Jekel, Water Sci. Technol., 2007, 56, 159-165.

14 T. Masciangioli and W. X. Zhang, Environ. Sci. Technol., 2003, 37, 102a-108a.

15 S. R. C. Rajajayavel and S. Ghoshal, Water Res., 2015, 78, 144153.
16 M. Danish, X. G. Gu, S. G. Lu and M. Naqvi, Environ. Sci. Pollut. Res., 2016, 23, 13298-13307.

17 J. Dong, C. Y. Wen, D. F. Liu, W. J. Zhang, J. T. Li, H. J. Jiang, C. W. Qin and M. Hong, J. Nanopart. Res., 2015, 17.

18 C. J. Ou, S. Zhang, J. G. Liu, J. Y. Shen, Y. Liu, X. Y. Sun, J. S. Li and L. J. Wang, Phys. Chem. Chem. Phys., 2015, 17, 2207222078.

19 S. Luo, P. F. Qin, J. H. Shao, L. Peng, Q. R. Zeng and J. D. Gu, Chem. Eng. J., 2013, 223, 1-7.

20 M. Khosravi and S. Arabi, Water Sci. Technol., 2016, 74, 343352.

21 P. P. Huang, Z. F. Ye, W. M. Xie, Q. Chen, J. Li, Z. C. Xu and M. S. Yao, Water Res., 2013, 47, 4050-4058.

22 T. Y. Liu, X. Yang, Z. L. Wang and X. X. Yan, Water Res., 2013, 47, 6691-6700.

23 J. Hur and M. A. Schlautman, Environ. Sci. Technol., 2003, 37, 4020.

24 C. B. Wang and W. X. Zhang, Environ. Sci. Technol., 1997, 31, 2154-2156.

25 Y. S. Li, J. S. Cao, B. B. Li, W. W. Li, F. Fang, Z. H. Tong and H. Q. Yu, Environ. Sci. Technol. Lett., 2016, 3, 36-40.

26 T. S. Yan, B. Y. Zhou, X. S. Xue and J. P. Cheng, J. Org. Chem., 2016, 81, 9006-9011.

27 X. Wang, F. Wei and W. Qi, Water and wastewater monitoring and analysis methods, China Environmental Science Press, Beijing, China, 2002.

28 X. Y. Wang, P. Wang, J. Ma, H. L. Liu and P. Ning, Appl. Surf. Sci., 2015, 345, 57-66.

29 Y. Q. Liu and G. V. Lowry, Environ. Sci. Technol., 2006, 40, 6085-6090.

30 M. Erbs, H. C. B. Hansen and C. E. Olsen, Environ. Sci. Technol., 1999, 33, 307-311.

31 T. Satapanajaru, P. J. Shea, S. D. Comfort and Y. Roh, Environ. Sci. Technol., 2003, 37, 5219-5227.

32 X. Q. Li, J. S. Cao and W. X. Zhang, Ind. Eng. Chem. Res., 2008, 47, 2131-2139.

33 H. Chen, H. J. Luo, Y. C. Lan, T. T. Dong, B. J. Hu and Y. P. Wang, J. Hazard. Mater., 2011, 192, 44-53.

34 L. J. Matheson and P. G. Tratnyek, Environ. Sci. Technol., 1994, 28, 2045-2053.

35 Y. P. Sun, X. Q. Li, J. S. Cao, W. X. Zhang and H. P. Wang, Adv. Colloid Interface Sci., 2006, 120, 47-56.

36 A. S. Adeleye, A. A. Keller, R. J. Miller and H. S. Lenihan, J. Nanopart. Res., 2013, 15, 1418-1435.

37 X. Q. Li, D. W. Elliott and W. X. Zhang, Crit. Rev. Solid State Mater. Sci., 2006, 31, 111-122.

38 A. M. Khalil, O. Eljamal, R. Eljamal, Y. Sugihara and N. Matsunaga, Synthesis, 2017, 6, 1.

39 Y. H. Liou, S. L. Lo, C. J. Lin, W. H. Kuan and S. C. Weng, J. Hazard. Mater., 2005, 126, 189-194.

40 C. L. Geiger, N. E. Ruiz, C. A. Clausen, D. R. Reinhart and J. W. Quinn, Water Res., 2002, 36, 1342-1350.

41 A. B. M. Giasuddin, S. R. Kanel and H. Choi, Environ. Sci. Technol., 2007, 41, 2022-2027.

42 D. G. Kim, Y. H. Hwang, H. S. Shin and S. O. Ko, Desalin. Water Treat., 2012, 49, 147-156. 
43 P. G. Tratnyek, M. M. Scherer, B. L. Deng and S. D. Hu, Water Res., 2001, 35, 4435-4443.

44 J. Niemeyer, Y. Chen and J. M. Bollag, Soil Sci. Soc. Am. J., 1992, 56, 135-140.
45 Z. P. Wen, Y. L. Zhang and C. M. Dai, Colloids Surf., A, 2014, 457, 433-440.

46 Y. Liu, T. Phenrat and G. V. Lowry, Environ. Sci. Technol., 2007, 41, 7881-7887. 